\title{
СИСТЕМА МОНИТОРИНГА ТЕМПЕРАТУРЫ ЗЕРНА В ЭЛЕВАТОРАХ И ЗЕРНОХРАНИЛИЩАХ
}

\author{
Масло А.Д. ${ }^{1}$, Кропачев Д.Ю. ${ }^{1}$, Неделько Д.Ю. ${ }^{1}$ \\ ${ }^{1}$ ОАО «Научно-производственное предприятие «Эталон»
}

Copyright (C) 2014 by author and the journal "Automation technological and business - processes”. This work is licensed under the Creative Commons Attribution International License (CC BY). http://creativecommons.org/licenses/by/4.0/

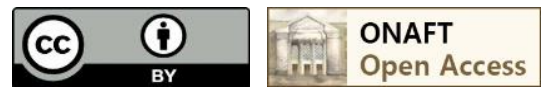

\begin{abstract}
Аннотация
В процессе хранения В зерне непрерывно происходят физические и биохимические реакции, сопровождающиеся выделением тепла и ведущие к самосогреванию. При самосогревании ухудшается качество зерна и происходит потеря массы сухих веществ. Мониторинг температуры зерна при хранении позволяет предотвратить нежелательные явления и снизить потери. Поэтому температура зерна является важнейшей характеристикой в процессе хранения.
\end{abstract}

\begin{abstract}
In the course of storage in grain continuously there are the physical and biochemical reactions, being accompanied allocation of heat and leaders to self-warming. At self-warming quality of grain worsens and there is a loss of mass of solids. Monitoring of temperature of grain at storage allows to prevent the undesirable phenomena and to reduce losses. Therefore temperature of grain is the major characteristic in the course of storage.
\end{abstract}

Ключевые слова

Зерно, мониторинг, температура зерна, многозонный датчик температуры, контроллер, система.

При хранении зерна в зерновой массе происходят различные физические и биохимические процессы. Отсутствие достаточного контроля за состоянием зерна и не своевременно проведенные мероприятия по предотвращению пагубного влияния этих процессов приводят к снижению его качества.

Правильно организованный мониторинг хранящихся зерновых и умелый правильный анализ полученных данных наблюдения позволяют своевременно предотвратить нежелательные явления и с минимальными затратами довести зерновую массу до состояния консервирования или реализовать ее без потерь.

При хранении непрерывно происходят биохимические процессы, которые влияют на качество зерна. Непрерывно выделяется влага. Относительная влажность воздуха в межзерновом пространстве при этом повышается, что приводит к новому увлажнению зерна, которое, приводит к накоплению тепла и соответственно повышению температуры свыше $35^{\circ} \mathrm{C}$ в зоне очага самосогревания.

Процесс самосогревания зерна, на начальной стадии его развития, достаточно длителен и характеризуется низкой скоростью увеличения температуры. С повышением температуры скорость роста температуры резко увеличивается, и, соответственно, сокращается время, отведенное для принятия мер по недопущению возгорания зерновой массы.

Контроль температуры зерна - наиболее эффективный и доступный практически способ отслеживания результатов биохимических процессов, протекающих в зерновой насыпи во время хранения. Температура зерновой насыпи позволяет судить о её состоянии в процессе хранения и принимать соответствующие меры для избежания ухудшения качества или порчи зерна. 


\section{㝋 ВИМІРЮВАННЯ ТЕХНОЛОГІЧНИХ ЗМІННИХ, ЩО ХАРАКТЕРИЗУЮТЬ СТАН ОБЛАДНАННЯ, ̈̈Х МЕТРОЛОГІЧНЕ ЗАБЕЗПЕЧЕННЯ}

Внедрение Системы температурного мониторинга для зернохранилищ позволяет:

- снизить потери от порчи и сушки зерна;

- минимизировать операционные затраты на хранение зерна.

Измерение температуры зерна можно выполнять различными способами, например:

- $\quad$ последовательные измерения температуры одним датчиком в заданных точках объекта с сохранением результатов для дальнейшей обработки;

- $\quad$ размещение множества датчиков в заданных точках зернохранилища с возможностью одновременного получения результатов со всех датчиков посредством проводной или беспроводной сети;

К достоинствам метода измерений одним датчиком можно отнести возможность минимальных затрат на измерительное оборудование и его поверку. Среди недостатков высокая трудоемкость проведения измерений и обработки результатов, дополнительная погрешность в случае, если после перемещения датчика не выдержано время, необходимое для установления теплового равновесия, искажения температурного распределения при нестационарных тепловых процессах.

Для минимизации этих недостатков датчики размещают во всех заданных точках объекта и объединяют в единую сеть. Устройство сбора данных (контроллер) с заданной периодичностью опрашивает все датчики сети, обрабатывает результаты, затем передает их на ПК либо сохраняет в памяти. Таким образом затраты времени на проведение измерений существенно сокращаются

В случае, когда расположение датчиков заранее известно и стационарно, удобнее использовать заранее смонтированные в единое изделие датчики и соединительный кабель - так называемые термокосы.

Система температурного мониторинга состоит из многозонного цифрового датчика температуры МЦдТ 1201 (термоподвески) и контроллеров цифровых датчиков температуры. В зависимости от конфигурации «системы» используемые контроллеры могут быть как портативными так и стационарными.

МЦДТ 1201 - герметичные термоподвески (рис. 1), предназначены для измерения зерна в силосных зернохранилищах, а также температуры жидкости в резервуарах. В качестве защитной оболочки термоподвесок этой серии используется герметичный металлорукав или металлопластиковая труба, которые дополнительно обеспечивают высокую механическую прочность.
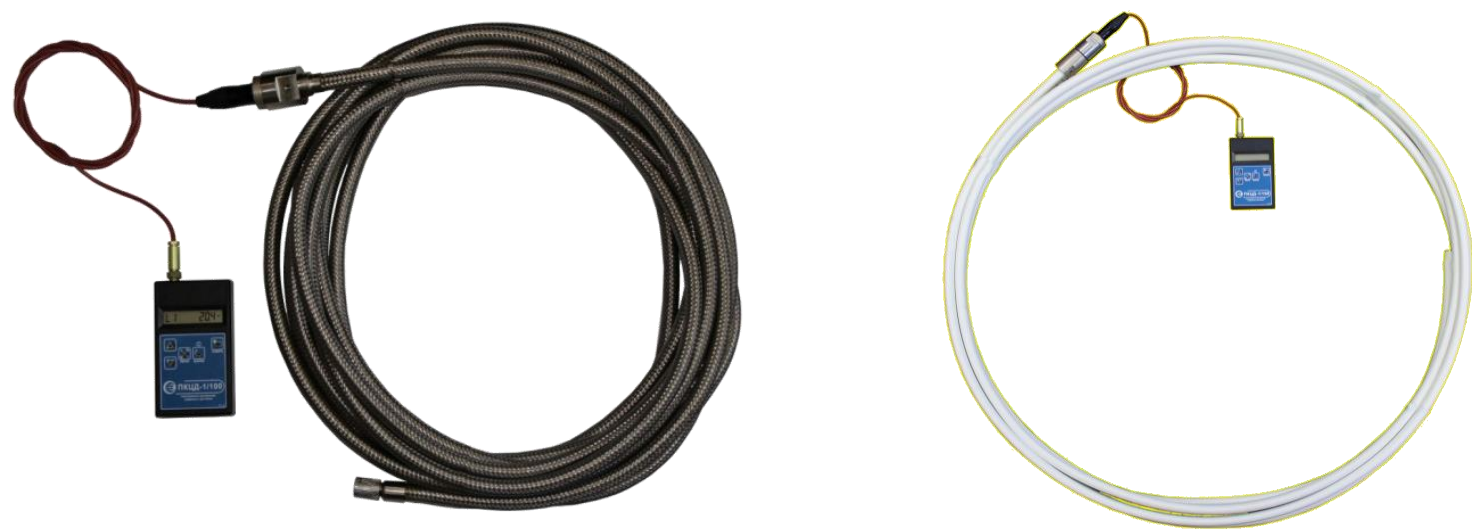

Рис. 1. Термоподвески серии МЦДТ 1201

Для регистрации данных цифровых датчиков температуры и термоподвесок, изготовленных из них, можно использовать портативные контроллеры, например ПКЦД-1/16 или ПКЦД-1/100 (рис. 2), максимальное количество одновременно подключаемых датчиков (или количество датчиков в термоподвеске) 16 или 100 соответственно. Эти контроллеры подключаются к разъему термоподвески и в течение нескольких секунд считывают и обрабатывают данные с датчиков и сохраняют во внутреннюю память. Далее данные сбрасываются на ПК либо сохраняются в энергонезависимую память и оператор может перейти к месту следующего замера. Дополнительно к ПКЦД-1/100 вместо термокосы можно подключить выносной датчик температуры и относительной влажности окружающего воздуха (рис. 3), при этом контроллер также производит расчет абсолютной влажности и точки росы. ПКЦД-1/100 может работать в режиме логгера, т.е. автоматически сохранять данные в энергонезависимой памяти с заданной периодичностью, ресурс автономной 


\section{$\underline{3}$ ВИМІРЮВАННЯ ТЕХНОЛОГІЧНИХ ЗМІННИХ, ЩО ХАРАКТЕРИЗУЮТЬ СТАН ОБЛАДНАННЯ, ЇХ МЕТРОЛОГІЧНЕ ЗАБЕЗПЕЧЕННЯ}

работы в режиме логгера составляет около 20 суток (изменяется в зависимости от емкости аккумулятора и окружающей температуры).
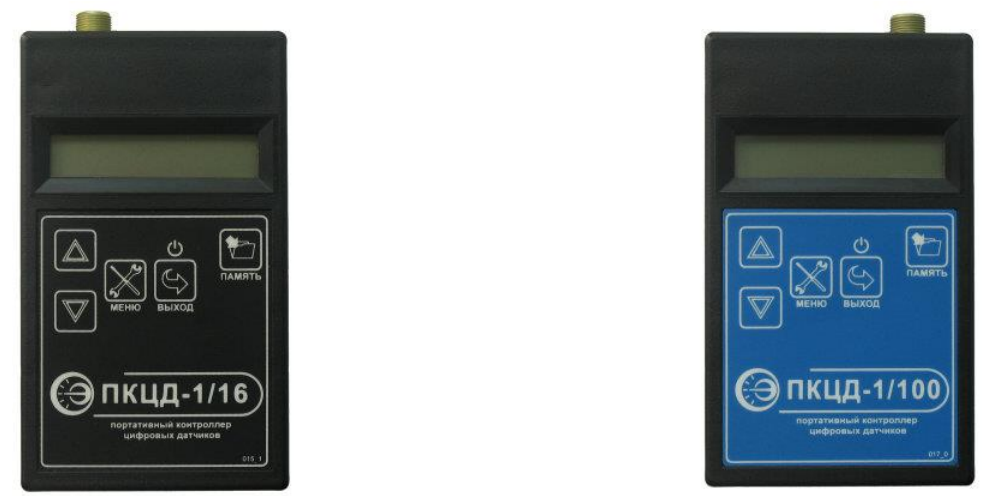

Рис. 2. Портативные контроллеры цифровых датчиков ПКЦД-1/16 и ПКЦД-1/100

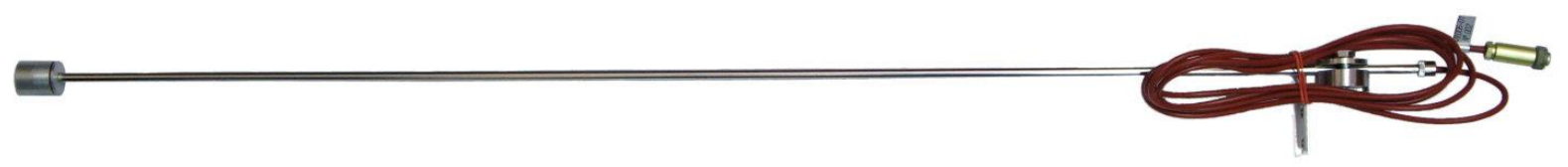

Рис. 3. Выносной датчик температуры и влажности

Если необходимо производить сбор данных длительное время и термоподвески установлены стационарно, целесообразно объединить все термоподвески в единую систему сбора данных (рис. 4).

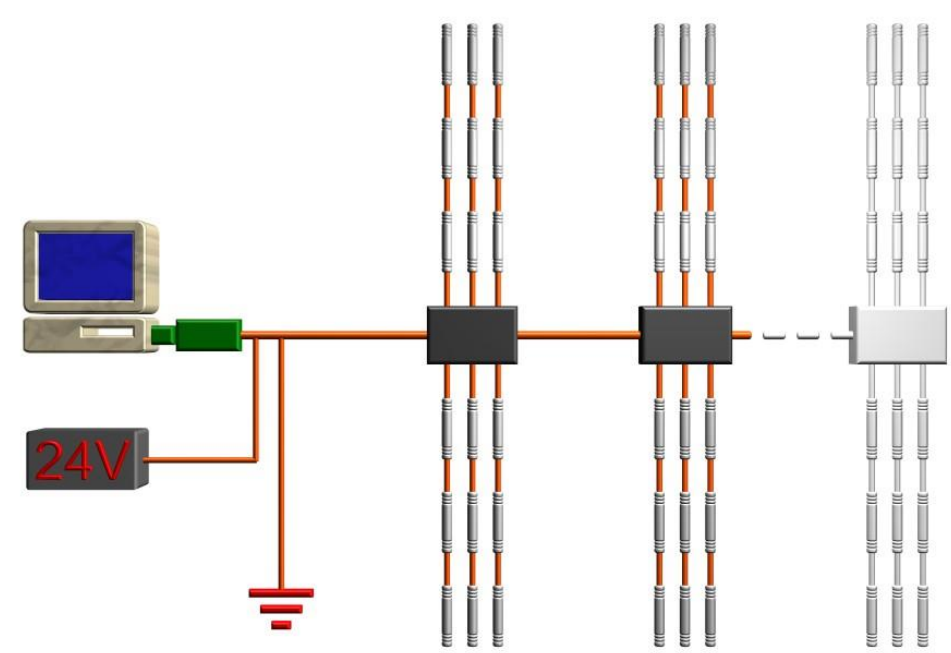

Рис. 4. Система сбора данных

Для этого были разработаны стационарные контроллеры СКЦД-1/100 (рис. 5) и СКЦД-6/200 (рис. 6). К СКЦД-1/100 подключается одна термоподвеска, содержащая до 100 датчиков, к СКЦД-6/200 можно подключить от 1 до 6 термоподвесок, содержащих суммарно до 200 датчиков. До 255 контроллеров при помощи кабеля типа "витая пара" объединяются в сеть RS-485 и через переходник USB/RS-485 подключаются к ПК, на котором установлена программа-сервер сети (рис. 7). 


\section{근 ВИМІРЮВАННЯ ТЕХНОЛОГІЧНИХ ЗМІННИХ, ЩО ХАРАКТЕРИЗУЮТЬ СТАН ОБЛАДНАННЯ, ЇХ МЕТРОЛОГІЧНЕ ЗАБЕЗПЕЧЕННЯ}

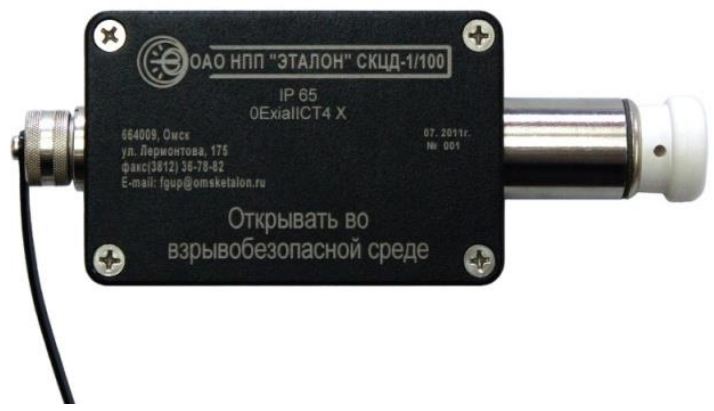

Рис. 5. Стационарный контроллер цифровых датчиков СКЦД-1/100

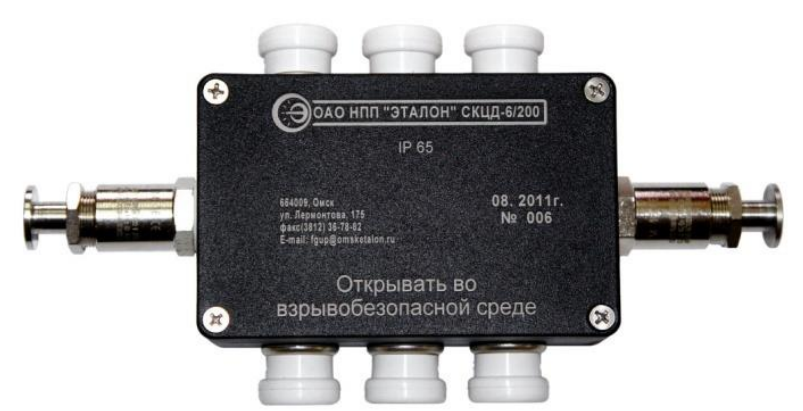

Рис. 6. Стационарный контроллер цифровых датчиков СКЦД-6/200

Программа сканирует сеть, идентифицирует найденные контроллеры и подключенные к ним термокосы, ведет мониторинг температур в реальном времени на графиках и в таблицах. Накопленные данные можно сохранить как в виде единого для всей системы файла, так и отдельно для каждой термоподвески. Для предотвращения потери данных при сбоях в работе ПК контроллер ведет запись данных в энергонезависимую память, структура и объем которой аналогичны ПКЦД-1/100. При необходимости потерянные данные можно восстановить, загрузив содержимое энергонезависимой памяти на ПК. Контроллеры СКЦД имеют степень защиты от пыли и воды IP65 и оснащены термостатом для подогрева электроники при работе при температурах окружающего воздуха ниже $-40^{0} \mathrm{C}$.
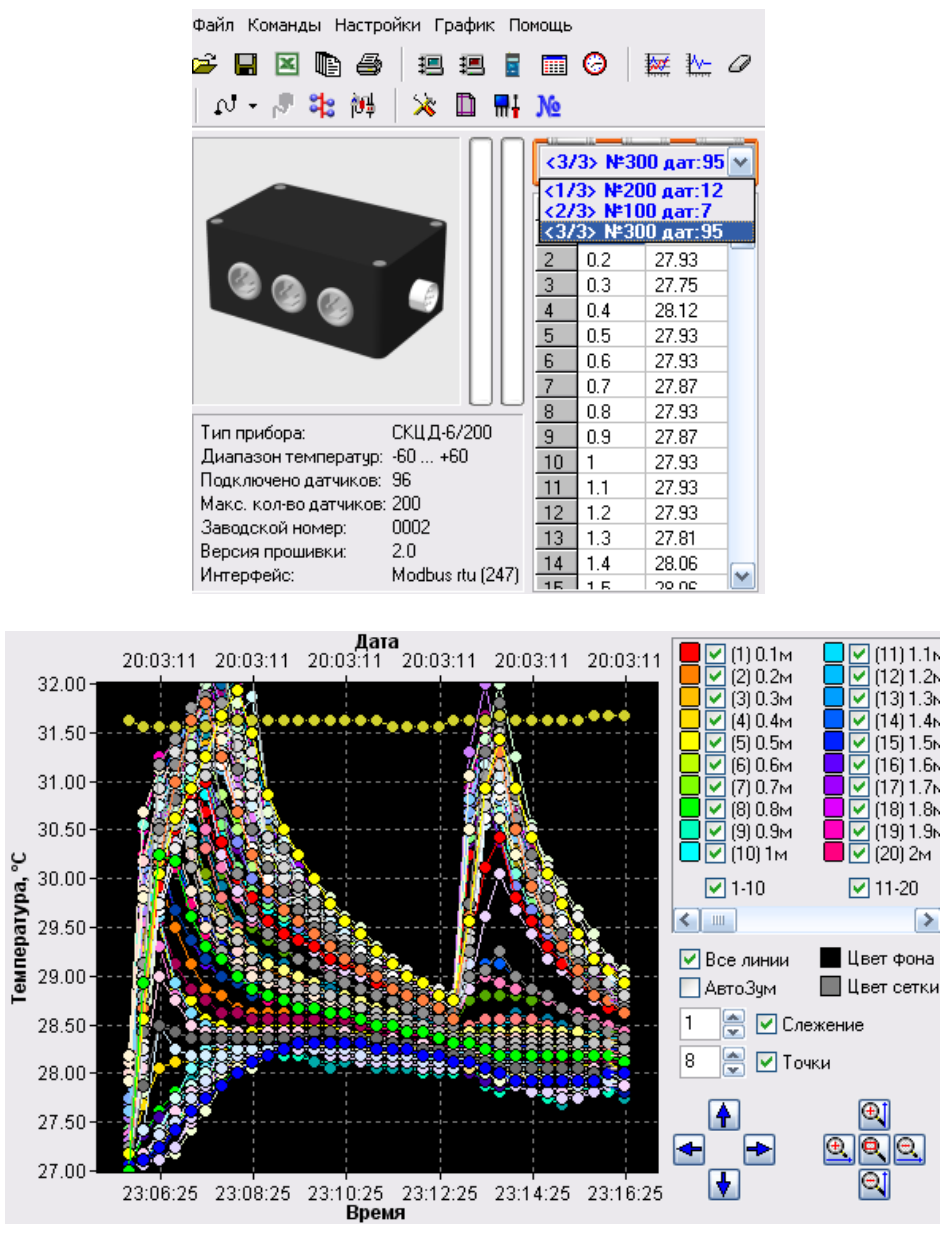

Рис. 7. Сервисное ПО Viper 